\title{
Discussion on Teaching Reform of Marketing Course Online Learning Space in Higher Vocational Colleges
}

\author{
Quanli $\mathrm{Wu}$ \\ Hunan Food and Drug Vocational College \\ Changsha, China
}

\begin{abstract}
Online learning space popularization is an important part of "three direct links" projects on educational informatization; it has triggered an educational and teaching revolution in Hunan province. Teaching online integrates openness, high quality and fairness, and brings a new opportunity for course reform of Vocational Colleges. Facing the existing problems of Higher Vocational Market Sales Management Courses, the paper analyzes the advantages of applying online learning space to course reform and teaching, discusses the teaching strategy of higher Vocational Market Sales Management Courses based on online learning space.
\end{abstract}

Keywords—informatization; marketing; course

\section{INTRODUCTION}

National Medium and Long-Term Educational Reform and Development Plan Outline (Year 2010-2020) clearly pointed out that completing popularized, fair, high-quality and life-long education by 2020 , basically realizing educational modernization. Information technology has a revolutionary influence on education development(1), and it is a fatal foundation and guarantee for educational modernization. Therefore, nine departments including ministry of education issued Notification on Current Several Key Tasks for Accelerating the Education Informatization jointly in 2012, putting online learning popularization as a main way to promote deep integration of information technology and education and teaching in the next period. Hunan province was leading in this respect all over the nation, it followed the thought" leading by government, participating by enterprises, applying by colleges, promoting by service", promoted educational modernization shifted from "technology-leading" to "application -leading", introduced online learning space that developed by enterprises based on Web2.0 and Cloud Computing, centered on online interactive learning, and resources were carried by Cluster Sever, innovated the development pattern of teaching resource, and started a new way for course reform and online teaching for vocational colleges.

At present, what widely applied and used in various places in Hunan is the World University City space platform (www.worluduc.com). The platform uses mutual help and mutual learning as core idea (2). On one hand, institutions can quickly set up interactive communication platform of online learning which regards joint construction and sharing of resources as the main body. On the other hand, each of the teachers and students can also set up an online learning space which has powerful functions and can be used for life respectively; schools depends on interactive communication platform of online learning, and teachers and students use online learning space, which can in real time to carry out regular management, teaching implementation, independent study and instant messaging, etc., truly realizing the management, teaching and learning with no limit of time and space. At the same time, it also creates new teaching organization form and teaching mode for school education, and the student-centered idea can be realized. Independent study mechanism can be set up. Besides, it promotes and forms new form of teaching and learning. This article discusses how to give play to the advantages of online learning space, integrate teaching materials of marketing course, and break the dilemmas of lacking enterprise real case and marketing typical case to enhance students' learning initiative and their autonomous, exploratory and cooperative learning ability and then improve teaching effect comprehensively.

\section{The Current Situation of Marketing COURSE TEACHING IN HIGHER VOCATIONAL COLLEGES}

The marketing course in higher vocational colleges mainly trains students about marketing knowledge and skills in fields related to goods, circulation and service, etc. Recently, through investigating 5 higher vocational colleges in a province in the central region which use food and drug, commerce and trade, logistics, finance and economics and insurance, etc. as industry background, the author finds that all these colleges set up related marketing major. But on the whole, marketing major especially the teaching goal of marketing course is difficult to fully realize. The core reason is that when learning, it is difficult for students to have the opportunity to practice with "real guns and bullets", and seriously lack true and typical case teaching, meanwhile, there are some inevitable problems existing in course teaching. Therefore, it causes that the course teaching effectiveness cannot reach basic requirements of employers of enterprises, etc.

Firstly, the course teaching lacks proper attraction. Course teaching bases on book knowledge or old cases, generally lacks the contents from marketing practice, leading to the fact that teachers and students cannot mutually form the sense of belonging of teaching and learning; the teaching 
methods adopted by teachers in teaching are also single and the means is older, which is difficult for teachers and students to form the effective interaction of teaching and learning; the textbook content tends to be conservative and traditional, and there are some phenomena of attaching great importance to knowledge and despising skills, which lead to the result that students' learning initiative is not very high.

Secondly, course theory knowledge is disjointed with practical operation. The emphasis of talent cultivation and teaching contents in higher vocational colleges shouldn't set up on the basis of professional scientific research frontier of disciplines, but bases on the requirements that employers have on students' skills literacy. In the implementation of teaching, teachers tend to pay attention to explain abstract concept principle, leading to the result that students generally lack manipulative ability. After graduation, a large number of students only know several basic concepts and general principles but cannot grasp the essence of marketing. The theory is seriously disconnected with practice.

Thirdly, the evaluation of students' learning effect is not scientific. Students learn marketing course and as for the examination and evaluation of their academic achievement, most of the higher vocational colleges still focus on closedbook written examination. Although some teachers occasionally combine internship and practical training to evaluate comprehensively, the proportion occupied by skill operation part is very small. This kind of teaching evaluation way doesn't conform to the curriculum and teaching evaluation theory of vocational education and the evaluation method for students' learning effect is not scientific and reasonable enough, which is difficult to objectively reflect students' understanding and application ability for marketing.

Fourthly, network learning resources are numerous and chaotic. At present, marketing involves the whole process of the economic field. The number of employees who devote themselves to it is numerous. Educator, practitioners and scholars write a huge number of digital education resources from different points of view or vision. Even though these provide rich reference resources for marketing major and students' learning about marketing course, because resources flow in the internet are of varying quality, for students and especially students who are beginners of this course, it is difficult to directly build knowledge content system and learning resource database to meet personal requirements.

Aiming at the common existence of the above mentioned problems, and base on the background of educational informatization that "everyone can enter the online learning space", the marketing course construction in higher vocational colleges should be bold and innovative, and on the basis of joint construction and sharing of excellent educational resources, continuously impels traditional education mode to transfer to independent and ubiquitous modern educational mode, promotes the interaction between teachers and students, teaching and learning, theory and practice, and promotes the unification of course teaching and students' interest, teaching process and teaching effect, classroom and outside class, then continually improves the effectiveness of teaching, intensifies students' specialty literacy and professional comprehensive ability.

\section{The Advantages That OnLine Learning SpaCE APPLIES TO TEACHING REFORM PRACTICE}

The online learning space built and used by Hunan basing on the platform of World University City has characteristics of individuation, openness, immediacy, sharing and interactivity, etc. It provides platforms for resources sharing, instant communication, independent study and cooperation between school and enterprise, etc. (3) and has a positive effect on deepening the teaching reform of marketing course in higher vocational colleges.

Firstly, the online learning space can fully realize educational resources sharing. On one hand, according to characteristics about knowledge, skills system of marketing course, teachers can independently design space column of this course, widely collect classic teaching videos about related celebrities and famous teachers, typical marketing cases of famous enterprises and celebrities, real difficulties and dilemmas of enterprises and products marketing, etc., and use special columns to record, sort and publish related contents; on the other hand, teachers can span the school to contact a group of marketing course teachers and span the boundary to organize several first-line experts of enterprise marketing to together build space group, design series of discussion topics, deeply discuss and communicate realistic problems of hot issues, key point and difficulties in marketing, and timely sort and refine the discussion results, which can overturn the enclosed traditional teaching that "one teacher forms a classroom", and realize the space teaching that "Everyone is my teacher and I am a teacher for them all", provide fresh teaching resources for students' independent learning and enhance students' learning interest.

Secondly, online learning space can promote the interaction between teachers and students. The emergence of network space and its extensive use in teaching set up a new type interactive communication platform between teachers and students. On one hand, students can study according to the materials that teachers put in the space, leave notes about the difficulties and problems that they meet in learning in teachers' space to ask for teachers' help and guidance; on the other hand, students can also put forward suggestions for teachers' teaching design, or hand in related typical cases and references collected by them for teachers to constantly improve course teaching content and optimize classroom teaching design, carry out online space teaching and lead students to deeply learn the course content and improve the efficiency of teaching performance.

Thirdly, online learning space can promote students' independent study. Carrying out online space teaching, according to the learning contents and learning tasks issued in real time by teachers, and the learning methods and learning steps provided by teachers, students can carry out independent study item by item, issue personal study notes, and participate in the discussion and communication between teachers and students, students and students within the group, which can effectively stimulate student's enthusiasm of 
independent study; at the same time, teachers use online space to proceed learning guidance, problems answer and homework correction, etc., integrate inside and outside the classroom, extend the space-time of classroom, which can better arouse students' interest, and greatly inspire students' learning initiative and enthusiasm.

\section{The TeAching Reform Strategy OF Marketing COURSE Which BASES ON ONLINE LEARNING SPACE}

Firstly, use online learning space to build rich teaching resources. Teaching material is the principal part of teaching resources, the important foundation for teachers to organize teaching and students to learn independently, also the teaching resource that teachers in vocational colleges generally lack (4). Using online space to organize and implement teaching needs teachers deconstruct and reconstruct the knowledge hierarchy of marketing course on the basis of the concept that working process designs teaching (5), design the construction frame of teaching resources database according to course content, real marketing tasks and typical marketing process as the basis, to "integrate" various forms of teaching resources such as concept base, method base, classical principle base, typical case base, training database, database of network reading books, teaching video resources database, professional knowledge extension libraries, etc. For this purpose, with the help of online learning space, students can learn flexibly and freely inside and outside class, and it extends students' classroom learning from being confined to the classroom to inside and outside the classroom. Meanwhile, set up five minutes class for teachers and students to build task-based resources, aggregate them into cards and brochures, build micro course and form the pattern of resource construction that "everyone builds and everyone shares".

Secondly, use online learning space to actively improve teaching methods. The content and theory knowledge of marketing course only base on the standard of "essential" and "enough to use" (6), teachers should take less teaching, brief and succinct teaching as the principal thing, and attach importance to highlight the teaching and training of practice. At first, in teaching, teachers should store all typical work tasks for students' learning in online space, and make students comprehensively contact marketing problems in reality to closely combine theory and practice; secondly, when teachers design the teaching process, as for the demonstration and explanation of every task, they should take problems as the starting point, adopt the methods of inspiration and guidance, and make students gradually grasp specific means to solve practical problems; thirdly, after the learning of each typical work task, according to the involved specific case, teachers should design series of discussion tasks and issue them in the online space for students to complete independently or cooperatively after class. At the same time, teachers should base on the space teaching to explore distinctive teaching organization form to promote active, collaborative, and investigative, independent learning, and then form an open, efficient new-type teaching mode(7).
Thirdly, use online learning space to set up diversified examination and evaluation system. After the course teaching goes to a certain stage, course teachers should store the course evaluation methods to online learning space in advance, let students together participate in and discuss examination and evaluation standard and the enforcement regulation, which not only helps students to timely prepare and grasp the examination and evaluation content, but also helps teachers to correct examination and evaluation standard in time according to students' practical situation and ensure the enforcement regulation be more operational. According to teaching progress, after students independently or cooperatively complete related tasks, teachers should in time organize the random inspection of task achievement and its quality to let students receive success, find their advantages and disadvantages, at the same time, mutually exchange and broad horizons of all the students.

\section{CONCLUSION}

To sum up, the rapid development and general application of information technology inevitably promote the deep integration of education teaching and information technology. Implementing the online space teaching of marketing course in higher vocational colleges not only helps to accelerate the construction of course teaching resources, but also is more beneficial to improve students' abilities to effectively acquire, analyze and process information resources, and the ability of teamwork and independent study, and cultivates students to become technical and skilled talents who can learn, apply and have ability..

\section{REFERENCES}

[1] National Medium and Long-Term Educational Reform and Development Plan Outline (2010-2020 year) [G]. State Council. 2010.7

[2] Wan Lanjun, Luo Haixia. Application of University City in Professional Teaching of Software Development in Higher Vocational Colleges [J] Fujian Computer. 2013(7)

[3] Huang Anyun, Liao Weihong, Tan Bi. The Course Construction of Psychological Health Education Based on University City Space in Higher Vocational Colleges [J]. Theory Research. 2013 (24).

[4] Chen Yongxian. Discussion on Professional Teaching Resource Construction of Vocational Education [J]. Vocational\& Technical Education Forum, 2011(8)

[5] Sun Rui. Curriculum Reform Ideas of Marketing in Higher Vocational Colleges Based on Work Process [J]. Education Teaching Forum. 2013 (10)

[6] Mei Jie. Brief Discussion on Practical Exploration of Marketing Course Reform in Higher Vocational Colleges [J]. Value Engineering. 2013(10)

[7] Chen Yongxian. Discussion on the Specialized Teaching Resources Base Construction of Vocational Education [J]. Vocational\& Technical Education Forum, 2011(8) 